\title{
RELAÇÃO DA PERCEPÇÃO DE JUSTIÇA NA AVALIAÇÃO DE DESEMPENHO COM FOLGA ORGANIZACIONAL DOS CONTROLLERS
}

\author{
Vanderlei dos Santos ${ }^{1}$ \\ Ilse Maria Beuren ${ }^{2}$ \\ Nelson Hein ${ }^{3}$
}

Resumo: O estudo objetiva verificar a relação da percepção de justiça organizacional na avaliação de desempenho com o nível de folga organizacional de controllers sob a forma de recursos financeiros e humanos, de facilidade no alcance das metas orçamentárias e de poder. Para tal, realizou-se pesquisa descritiva com abordagem quantitativa, por meio de um levantamento. Um questionário foi enviado aos controllers de 108 empresas das regiões Sul e Sudeste do Brasil, listadas entre as 150 melhores empresas para se trabalhar, conforme a revista Você S/A, e se obteve um total de 26 respostas. Os resultados mostram, na análise da relação de cada dimensão de justiça com folga organizacional, que todas as dimensões estão relacionadas com folga de poder, sob o aspecto de participação orçamentária. Além disso, há relação entre justiça processual e justiça informacional com folga de recursos humanos. Entretanto, na análise das dimensões de justiça de forma global, observa-se apenas relação com a participação orçamentária. Concluiu-se com base nas respostas dos controllers ao instrumento de pesquisa, que alguns tipos de folga organizacional estão relacionados com os sentimentos de justiça na avaliação de desempenho, cujas dimensões têm efeitos distintos na relação desses profissionais com a empresa em que trabalham, uma proposição a ser investigada.

Palavras-chave: Justiça organizacional. Folga organizacional. Avaliação de desempenho. Controllers.

\footnotetext{
11 E-mail: vanderleidossantos09@gmail.com. Doutorando em Contabilidade na Universidade Federal de Santa Catarina - UFSC. Professor da Universidade do Estado de Santa Catarina - UDESC.

22 E-mail: ilse.beuren@gmail.com. Doutora em Controladoria e Contabilidade pela FEA/USP. Professora da Universidade Federal de Santa Catarina - UFSC

3 E-mail: hein@furb.br. Doutor em Engenharia de Produção pela EPS/UFSC. Professor do Programa de Pós-Graduação em Ciências Contábeis da Universidade Regional de Blumenau - FURB.

- DOI: http://dx.doi.org/10.14392/asaa.2015080104

- Artigo recebido em 13/08/2014. Submetido para 2a rodada de avaliação em 28/11/2014. Aprovado em 14/04/2015.
} 


\title{
RELATIONSHIP BETWEEN THE PERCEPTION OF JUSTICE IN PERFORMANCE EVALUATION AND CONTROLLERS' ORGANIZATIONAL SLACK
}

\begin{abstract}
The study aims to verify the relationship between the perception of organizational justice in performance evaluation and the level of controllers' organizational slack in the form of financial and human resources, of the easiness in reaching the budgetary and power targets. For such, a descriptive research with quantitative approach was conducted through a survey. A questionnaire was sent to the controllers of 108 companies in the South and Southeast of Brazil, listed among the 150 best companies to work, according to the magazine Você S/A, and obtained a total of 26 responses. In the analysis of the relationship between each dimension of justice and the organizational slack, the results show that all dimensions are related power slack, in the aspect of budgetary participation. Also, there is a relationship between procedural justice and informational justice and the slack of human resources. However, in the global analysis of the justice dimensions, it is observed a relationship only with the budgetary share. Based on the controllers' responses to the instrument, it was concluded that some types of organizational slack are related to the sense of justice in the performance evaluation, whose dimensions have distinct effects on the relationship between these professionals and the company they work for, a proposition to be investigated.
\end{abstract}

Keywords: Organizational justice. Organizational slack. Performance evaluation. Controllers.

\section{INTRODUÇÃO}

A percepção de justiça organizacional é um dos valores que os empregados tendem a ser sensíveis e que pode melhorar o comprometimento individual das pessoas na organização em que trabaIham (Tremblay, Sire \& Balkin, 2000). Para Omar (2006), justiça organizacional refere-se à percepção dos empregados sobre o que é justo ou injusto dentro das organizações. O termo justiça organizacional descreve o papel da justiça no que refere-se diretamente ao local de trabalho (Greenberg, 1990). Especificamente, a justiça organizacional se preocupa com o modo como os empregados determinam se foram tratados de forma justa e a maneira pela qual essas determinações influenciam comportamentos e atitudes posteriores relacionadas com o trabalho (Greenberg, 1990).

Para Colquitt (2001), a abordagem da justiça organizacional tem se tornado um constructo importante nas Ciências Sociais. Inicialmente pesquisadores abordaram a justiça com foco nos resultados das decisões, denominando-a de justiça distributiva. Posteriormente, estudos concentraram-se na análise dos processos que estabelecem as diretrizes que conduzem à tomada de decisão, denominada de justiça processual. Contudo, com o avanço das pesquisas uma terceira dimensão foi introduzida, caracterizando a relação interpessoal estabelecida pela interação entre chefias e subordinados, denominada de justiça interacional, esta desmembrada em interpessoal e informacional. (Colquitt, 2001).

Segundo Langevin e Mendoza (2013), estudos recentes têm utilizado os preceitos da Justiça Organizacional na área da Contabilidade Gerencial, para pesquisar os efeitos da justiça percebida nas atitudes 
e comportamentos dos gestores. No entanto, identificaram-se pesquisas anteriores que tangenciam esse enfoque, como na avaliação de desempenho (Folger; Konovsky, 1989, Cropanzano, Prehar, Chen, 2002, Sotomayor, 2006), mudança organizacional (Folger, Skarlicki, 1999), políticas salariais (Folger, Konovsky, 1989), promoções (Lemons, Jones, 2001), processos de seleção (Gilliland, 1994), processo orçamentário (Maiga, Jacobs, 2007).

Quanto aos efeitos da percepção da justiça organizacional, resultados de pesquisas empíricas mostram que a percepção de justiça pode impactar a satisfação no trabalho (Colquitt et al., 2001, Blau, 1999), o comprometimento organizacional (Folger \& Konovsky, 1989, Ambrose \& Cropanzano, 2003), comportamentos de cidadania organizacional (Rupp \& Cropanzano, 2002), intenções de turnover (Masterson et al., 2000), desempenho (Colquitt et al., 2001, Cohen-Charash \& Spector, 2001) e redução da folga orçamentária (Özer, Yilmaz, 2011). Nesta pesquisa, analisa-se a percepção de justiça na avaliação de desempenho e sua relação com a folga organizacional.

A visão predominante de folga organizacional utilizada na literatura é a baseada em Cyert e March (1963), contida na Teoria Comportamental. Os autores a conceituam como o excesso de recursos disponíveis para a empresa acima do necessário para atender as suas necessidades imediatas. Refere-se a uma disparidade entre os recursos disponíveis na organização e os necessários para manter a coalizão. Neste estudo, a folga organizacional é abordada nas perspectivas de recursos financeiros, recursos humanos, metas orçamentárias e poder (à luz da participação orçamentária e autonomia das decisões) numa área organizacional específica, a folga dos controllers.

A folga dos controllers está relacionada ao excesso de recursos, tanto financeiros como de pessoas em seu departamento, e também ao nível de poder, sendo este relacionado à participação no processo orçamentário e autonomia nas decisões. Beck e Beuren (2013) explicam que a folga de poder se manifesta a partir das decisões no processo orçamentário e assimetria informacional. Está relacionada ao poder na obtenção de informações, recursos, decisão no processo orçamentário, flexibilidade e participação orçamentária, autonomia nas decisões. Para Mallidou et al. (2011), o uso de medidas unicamente financeiras na investigação da folga organizacional, pode ignorar outras perspectivas importantes, que afetam comportamentos individuais e resultados das organizações.

Algumas pesquisas sobre justiça organizacional e folga foram identificadas na literatura contábil. Libby (1999) investigou a relação entre o uso de um processo orçamentário justo e o desempenho dos funcionários. Maiga e Jacobs (2007) analisaram a relação entre participação orçamentária, justiça distributiva, justiça processual, confiança gerencial, comprometimento com as metas e propensão dos gestores para criar folga orçamentária. Özer e Yilmaz (2011) averiguaram os efeitos da justiça processual sobre a eficácia do controle orçamentário, ética no ambiente de trabalho e propensão para criação de folga orçamentária. Em âmbito nacional, Klein et al. (2014) verificaram se a percepção de justiça organizacional nos sistemas de controle gerencial aumenta o comprometimento e a confiança dos gestores.

Entretanto, alguns desses estudos, ao abordar a questão da folga, concentram-se num tipo específico, como a folga orçamentária. Além disso, outras pesquisas consideraram apenas a justiça processual e/ou distributiva nas investigações, sendo que as relações interpessoais também estão envolvidas no contexto da avaliação de desempenho. A lacuna percebida nestes estudos motivou contemplar nesta 
pesquisa as quatro dimensões de justiça na avaliação desempenho e abordar sua relação com a folga organizacional. Desta forma, busca-se responder a seguinte questão de pesquisa: Qual a relação entre as dimensões de justiça na avaliação de desempenho com a folga organizacional? O objetivo do estudo é verificar a relação da percepção de justiça organizacional na avaliação de desempenho com o nível de folga organizacional de controllers sob a forma de recursos financeiros e humanos, de facilidade no alcance das metas orçamentários e de poder.

A investigação da percepção de justiça na avaliação de desempenho desses profissionais é importante para as organizações, uma vez que tendem a ser pessoas com papel diferenciado no suporte ao processo de gestão das empresas. Argumenta-se que as atividades que o controller realiza exigem percepções de justiça para que se sinta motivado a analisar e prover informações que permitam aos gestores buscar alternativas de decisão (Birnberg, Luft \& Shields, 2008). Isto implica determinado nível de folga de recursos, de participação no processo orçamentário e de autonomia, de modo que o profissional consiga realizar suas atividades sem a pressão de inexistência de folga organizacional, conforme evidências empíricas do estudo de Indjejikian e Matejka (2006).

O estudo busca contribuir no sentido de aprofundar o entendimento de justiça organizacional com a sistemática de avaliação de desempenho, nas perspectivas de justiça distributiva, procedimental e interacional, nas abordagens interpessoal e informacional (Colquitt et al. 2001 \& Sotomayor, 2007), focalizando os controllers de organizações. O conhecimento é ampliado ao relacionar a folga organizacional com as percepções de justiça, investigando suas interfaces, cuja abordagem foi pouco observada na literatura. Klein et al. (2014) comentam que no Brasil, pesquisas que abordam sobre justiça organizacional são esparsas, apesar da relevância deste campo de investigação, principalmente pela sua utilidade potencial na melhoria das relações entre trabalhadores e organizações.

\section{REFERENCIAL TEÓRICO}

\subsection{JUSTIÇA ORGANIZACIONAL}

O conceito de justiça é reconhecido como um componente crítico para o funcionamento eficaz das organizações (Greenberg, 1990) e como uma questão de interesse central aos empregados. Greenberg (1987) explica que as primeiras teorias (Homans, 1961, Adams, 1965 \& Rawls, 1971) estavam principalmente preocupadas com a aplicação de princípios de justiça para questões gerais de interação social. O sucesso limitado dessas teorias gerais para explicar o comportamento organizacional levou pesquisadores a buscar uma teoria mais específica de justiça, como a equidade no local de trabalho. Assim, o termo justiça organizacional evoluiu para descrever o papel da justiça em questões de trabalho (Greenberg, 1987).

A justiça organizacional refere-se à percepção do indivíduo sobre o que é justo ou injusto no contexto do trabalho (Wentzel, 1998). Desse modo, o indivíduo julga o tratamento recebido como mais ou menos justo, conforme a avaliação que ele faz entre suas expectativas e as informações e os sentidos que ele capta do ambiente organizacional (Ribeiro \& Bastos, 2010). Os estudos sobre justiça organizacional evoluíram sob diferentes abordagens ao longo do tempo, atualmente com quatro dimensões: justiça distributiva, justiça processual, justiça interacional interpessoal e justiça interacional informacional (Langevin, Mendoza, 2013).

A justiça distributiva preconiza que os gestores estão preocupados com a justiça de distribuição de recursos, tais como salários, recompensas, promoções (Adams, 1965, Langevin \& Mendoza, 2013). 
A abordagem predominante para a análise de questões da justiça distributiva é a Teoria da Equidade de Adamns (1965). Conforme esta Teoria, as pessoas determinam se elas foram tratadas de forma justa ao analisar a existência da proporcionalidade entre os resultados/recompensas recebidas e o esforço despendido para atingi-las, comparando suas recompensas com as de outros indivíduos nas mesmas condições. (Langevin, Mendoza, 2013).

Os estudos desta dimensão de justiça estão principalmente direcionados à forma como as percepções da justiça distributiva afetam as atitudes e comportamentos dos empregados no local de trabalho (Wentzel, 1998). Pesquisas mostram que a justiça distributiva está fortemente relacionada com satisfação no trabalho e intenção de permanecer na organização (Gomide Jr, 1999, Fields, Pang \& Chiu 2000, Deconinck, Stilwell, 2004 \& Chiuzi, 2006). Quanto maior for a percepção de justiça distributiva, maior será a satisfação no trabalho e aumentará a intenção do indivíduo de permanecer na empresa.

Considerando que a justiça distributiva refere-se à equidade dos resultados, a justiça processual recai sobre a equidade percebida nos procedimentos utilizados para determinar decisões organizacionais, tais como: processos de seleção, sistemas de avaliação de desempenho, procedimentos de aumentos salariais, de regras para alocação de recursos (Wentzel, 1998 \& Sotomayor, 2007). Seu objeto de estudo são os meios utilizados para a consecução dos fins alcançados. Por isso é também conhecida como a justiça dos meios (Rego, 2002, Ribeiro \& Bastos, 2010).

Wentzel (1998) explica que as primeiras tentativas para desenvolver uma teoria da justiça processual surgiram a partir dos estudos realizados por Thibaut e Walker $(1975 ; 1978)$ em processos de resolução de litígios, no qual preconizam a importância do controle do processo para existir percepção de justiça. Conforme Wentzel (1998), Thibaut e Walker (1975) concluíram que os procedimentos considerados mais justos pelas partes envolvidas são aqueles que lhes conferem a oportunidade de expressar suas opiniões (efeito de voz).

Porém, Leventhal et al. (1980) expõem uma teoria mais ampla, identificando seis critérios de equidade processual: a) consistência das regras e normas a serem aplicadas ao longo do tempo; b) ausência de vieses e interesses pessoais das pessoas que tomam as decisões; $c$ ) veracidade das informações dadas aos indivíduos envolvidos pela decisão; d) representatividade dos envolvidos no processo decisório; e) ética no que se refere aos valores morais; e f) possibilidade de correção e modificação das decisões injustas. Greenberg (1987) destaca ainda a possibilidade de apelar contra decisões desfavoráveis como um fator para considerar determinado procedimento como sendo justo.

Seguindo em uma linha de tempo, os estudos de justiça organizacional focalizaram uma nova dimensão, a justiça interacional. Esta foi introduzida por Bies e Moag (1986) e concentra-se na importância da qualidade do tratamento interpessoal que os indivíduos recebem quando os procedimentos são implementados, bem como após essa mesma implementação (Sotomayor, 2007). A justiça interacional significa que as pessoas são sensíveis à qualidade do tratamento interpessoal que recebem durante a promulgação dos procedimentos da organização (Wentzel, 1998).

A justiça interacional foi ainda dividida em justiça interpessoal e justiça informacional (Greenberg, 1993). A justiça interpessoal reflete o grau conforme o qual as pessoas são tratadas com cortesia, dignidade e respeito pelas autoridades ou pelas terceiras partes envolvidas na execução de procedimentos (Wentzel, 1998 \& Sotomayor, 2007). Ao passo que a justiça informacional está relacionada às informações e explicações sobre as decisões tomadas, em termos de clareza, oportunidade e abrangência (Ribeiro \& Bastos, 2010). A justiça informacional concentra-se na explicação oferecida pelas organizações sobre 
as tomadas de decisões, sobre o como e o porquê que algumas decisões são tomadas e direcionados para um determinado caminho (Pereira, 2008).

Depreende-se que as quatro dimensões de justiça organizacional possuem características distintas e são suscetíveis de provocar atitudes e comportamentos nas pessoas dentro da organização. Para ilustrar, a Figura 1 sintetiza as principais características das quatro dimensões de justiça organizacional.

Figura 1: Síntese conceitual das quatro dimensões de justiça organizacional

\begin{tabular}{|c|c|c|}
\hline \multicolumn{2}{|c|}{ Dimensões } & Descrição conceitual \\
\hline \multicolumn{2}{|c|}{ Distributiva } & $\begin{array}{l}\text { Focaliza-se no conteúdo, isto é, na justiça dos fins alcançados ou } \\
\text { obtidos. Diz respeito, por exemplo, , aos salários, classificações obtidas } \\
\text { nas avaliações de desempenho, sanções disciplinares, promoções, } \\
\text { aceitação/rejeição de candidatos, fatia orçamentária atribuída às } \\
\text { unidades organizacionais, lucros distribuídos aos trabalhadores. }\end{array}$ \\
\hline \multicolumn{2}{|c|}{ Processual } & $\begin{array}{l}\text { Focaliza-se no processo, ou seja, na justiça dos meios usados para } \\
\text { alcançar tais fins. Concerne, por exemplo, aos procedimentos usados } \\
\text { nos acréscimos salariais, nos processos disciplinares, nas avaliações de } \\
\text { desempenho, nos processos de recrutamento e seleção. }\end{array}$ \\
\hline \multirow{2}{*}{ Internacional } & Interpessoal & $\begin{array}{l}\text { Incide sobre o grau em que o superior adota um tratamento } \\
\text { digno e respeitador para com os seus colaboradores. }\end{array}$ \\
\hline & Informacional & $\begin{array}{l}\text { Centra-se no grau em que o superior fornece informações } \\
\text { e explica/justifica as decisões que afetam as pessoas. }\end{array}$ \\
\hline
\end{tabular}

Fonte: Souto e Rego (2003)

Assmar, Ferreira e Souto (2005) comentam que os pesquisadores têm também abrangido diversos contextos organizacionais em busca dos elementos que possam eliciar avaliações de justiça, ou seja, quais são os antecedentes da justiça organizacional, quais os fatores que são capazes de suscitar julgamentos de justiça distributiva, processual, interpessoal e informacional. Neste estudo, investiga-se a percepção de justiça organizacional no contexto de avaliação de desempenho e sua relação com a folga organizacional.

\subsection{PERCEPÇÃO DE JUSTIÇA E FOLGA ORGANIZACIONAL}

Nohria e Gulati (1997) mencionam que a folga organizacional está relacionada com o excesso de recursos em uma organização que está além do mínimo necessário para produzir um dado nível de resultados. Dimick e Murray (1978) conceituam a folga organizacional como sendo recursos que uma organização tenha adquirido e que não estão comprometidos com uma despesa necessária.

Para Danneels (2008), a folga organizacional é caracterizada pela folga de recursos, uma reserva de recursos que estão em excesso além do necessário para a continuação imediata das operações da empresa, e estão, portanto, disponíveis para gastar em atividades extraordinárias. O autor elucida a folga de recursos como sendo de recursos humanos e financeiros que não são consumidos para a continuidade das operações diárias da empresa. Incluem-se nesses recursos: capacidade não utilizada, despesas de capital desnecessárias, oportunidades inexploradas, excesso de trabalhadores. Pode-se considerar ainda como folga, um orçamento além do mínimo necessário (Nohria, Gulati, 1996 \& Danneels, 2008).

Beck e Beuren (2014), em revisão de literatura realizada sobre folga organizacional, observaram que a maioria dos autores, em que se destaca Bourgeois (1981), utilizaram unicamente os recursos financeiros para explicar e medir a folga organizacional. Damanpour (1991), Nohria e Gulati (1996) advertem que há outras modalidades de folga mais subjetivas, como o poder e relações políticas, recursos humanos, capacidade utilizada na produção, espaço físico e de tempo, que merecem atenção nas pesquisas. 
Este estudo utiliza-se de características predominantemente subjetivas da folga organizacional, a saber: (i) folga quanto à facilidade no alcance das metas orçamentárias; (ii) folga de recursos financeiros; (iii) folga de recursos humanos; e (iv) folga de poder. Na Figura 2 apresentam-se os tipos de folga analisados e sua respectiva conceituação.

Figura 2: Tipos de folga abordados na pesquisa

\begin{tabular}{|c|l|}
\hline Tipos de folga & \multicolumn{1}{|c|}{ Conceituação } \\
\hline $\begin{array}{c}\text { Facilidade no alcance das metas } \\
\text { orçamentárias }\end{array}$ & $\begin{array}{l}\text { Caracteriza-se pela facilidade no cumprimento do orçamento, uma } \\
\text { vez que existe folga. } \\
\text { Quando o orçamento é de fácil cumprimento, não haverá muito esforço } \\
\text { das pessoas para cumprir as metas do orçamento. }\end{array}$ \\
\hline Recursos financeiros & $\begin{array}{l}\text { Recursos em espécie ou líquidos além do suficiente para utilização } \\
\text { imediata não prevista. }\end{array}$ \\
\hline Recursos humanos & Número de pessoas ou horas de trabalho além do mínimo necessário. \\
\hline Poder & $\begin{array}{l}\text { Está relacionada ao poder na decisão de informações, recursos, decisão } \\
\text { no processo orçamentário, flexibilidade e participação orçamentária, } \\
\text { autonomia nas decisões. Caracteriza-se pelo poder informacional } \\
\text { existente na empresa, sob o aspecto de novas fontes de informação e do } \\
\text { acesso às informações na empresa. Também pode estabelecer-se pela } \\
\text { autonomia concedida aos diretores, gestores e lideranças na tomada } \\
\text { de decisões no planejamento e no processo orçamentário. }\end{array}$ \\
\hline
\end{tabular}

Fonte: Adaptado de Indjejikian e Matejka (2006), Beck e Beuren (2013), Beck e Beuren (2014).

Além disso, estes tipos de folga são analisados em um departamento específico, o departamento de controladoria, contemplando no caso, a folga organizacional dos controllers e sua relação com a percepção de justiça no processo de avaliação de desempenho.

\subsubsection{Percepção de justiça na avaliação de desempenho e folga quanto à facilidade no alcance das metas orçamentárias}

O orçamento é um instrumento vital às organizações para direcionar as atividades e os esforços dos empregados em prol de objetivos comuns da organização (Covaleski et al., 2003). Magner et al. (2006) esclarecem que os gestores são elementos-chave no orçamento organizacional, visto que estão envolvidos tanto na preparação do orçamento da sua unidade quanto acompanham se as atividades de sua unidade são realizadas de acordo com o orçamento. Desta forma, os procedimentos orçamentários e a destinação de recursos afetam as atitudes e comportamentos desses gestores. Estas reações decorrem do fato de que o orçamento da unidade afeta as recompensas pessoais, materiais e psicológicas, que os gestores são capazes de usufruir a partir da sistemática de avaliação de desempenho.

Van Der Stede (2000) comenta que a organização pode vincular as recompensas materiais dos gestores, tais como, pagamento de bônus em função do desempenho alcançado pela unidade organizacional. Merchant e Manzoni (1989) explicam que os gestores cuja unidade alcança seus resultados podem ser mais propensos a se ver como um vencedor, o que aumenta sua autoestima. Além disso, acredita-se que o recebimento de recompensas materiais e psicológicas acarreta no aumento da percepção de justiça na avaliação de desempenho. Assim, formula-se a primeira hipótese da pesquisa:

H1: Há relação positiva entre percepção de justiça na avaliação de desempenho e folga quanto à facilidade no alcance das metas orçamentárias. 
Em se tratando da folga organizacional, Hopwood (1972) verificou em seu estudo que os gestores avaliados com base no orçamento são mais suscetíveis à criação da folga. Segundo Schiff e Lewin (1968), a ênfase no orçamento é uma das principais justificativas para a criação de folga, principalmente se na avaliação de desempenho o alcance das metas estiver aliado ao sistema de recompensas. Segundo Dunk e Perera (1997) e Waller (1998), se os gestores percebem suas recompensas dependentes da realização do orçamento, eles podem gerar folga em seus orçamentos por meio do processo de participação, tornando-o mais fácil de ser atingido. Dunk (1990) também destaca que os gestores podem alterar o processo orçamentário criando um orçamento mais fácil de atingir, ou seja, com folga orçamentária.

Desse modo, a não rejeição da hipótese $\mathrm{H} 1$ indicará que quando os gestores percebem maior justiça na avaliação de desempenho, os orçamentos são fáceis de atingir e/ou atingíveis com esforço normal.

\subsubsection{Percepção de justiça na avaliação de desempenho e folga de recursos financeiros e humanos}

O controller é um profissional que deve possuir conhecimento acerca da organização na qual trabalha e precisa desenvolver habilidades específicas para o exercício da função. Frezatti et al. (2009) mencionam que são exigidas do controller diversas outras habilidades, tais como: compreensão do negócio da entidade; entendimento e participação dos problemas dos executivos das várias áreas, fornecendo apoio no que concerne às suas habilidades e competências; conhecimentos de gestão, domínio de conhecimentos em contabilidade, custos, despesas, tributos, tecnologia de informação; noções básicas e fundamentais de economia, sociologia, psicologia e estatística; espírito de liderança; bom raciocínio lógico.

Ferrari et al. (2013) identificaram as funções e atribuições do controller solicitadas pelas empresas brasileiras, no processo de recrutamento no mercado de trabalho nacional. Os autores constataram que quanto às funções, as mais requisitadas são: o gerenciamento da contabilidade, o controle fiscal e tributário, o planejamento estratégico e os relatórios gerenciais. No que refere-se às competências, perceberam que as mais destacadas são: visão global de mercado, dinamismo, liderança e proatividade. O conhecimento em IFRS/ERP foi considerado importante, no decorrer do período pesquisado e passará a ser solicitado não mais como competência, e sim como função a ser desempenhada.

Deste modo, percebe-se que o controller exerce um papel diferenciado nas organizações comparativamente aos outros gestores. Além de gerenciar seu departamento, necessita assessorar outras áreas organizacionais e participar da parte estratégica das organizações. Para tanto, é necessário que haja disponibilidade tanto recursos financeiros quanto humanos para a obtenção de êxito e, consequentemente, sentimento de justiça.

Os gerentes das unidades que recebem uma alocação de recursos relativamente grande podem receber maiores recompensas materiais, se mais recursos facilitam um maior desempenho da unidade (Magner et al., 2006). Esses gerentes também podem perceber maiores recompensas psicológicas, se os trabalhadores subordinados da unidade concederem ao gerente maior status e reconhecimento, porque eles percebem a maior alocação de recursos como prova da eficácia do gerente da unidade (Magner et al., 2006).

Davila e Wouters (2005) realizaram uma pesquisa ao longo de 24 meses, em quatro centros de logística de uma empresa fabricante de discos de computadores. No estudo de caso realizado, obti- 
veram evidências empíricas sobre o modo como a empresa faz seu orçamento com recursos financeiros adicionais, com a intenção de motivação, para facilitar a tarefa dos gestores na consecução dos objetivos da empresa.

Beck e Beuren (2014) destacam que a modalidade de folga de recursos financeiros é apontada também como base para outras modalidades de folga: a) possibilita a contratação de um número maior de funcionários, e os custos com seu treinamento e capacitação (folga de recursos humanos); b) viabiliza a compra de máquinas, equipamentos, ampliações de espaços físicos e capacidade produtiva (folga de recursos físicos); c) permite suportar o ônus financeiro relacionado a infraestrutura de tecnologia da informação (folga de poder na assimetria da informação).

Em relação à folga de recursos humanos, Lawson (2001) constatou que quando o trabalho é realizado por uma quantidade menor de pessoas e/ou com menos apoio financeiro, a pressão por produção aumenta, e o tempo de experimentação e colaboração criativa se torna escasso. Desta forma, possuir folga organizacional de recursos humanos possibilita a realização de novas tarefas, além de treinamento e capacitação. Neste sentido, foi elaborada a segunda hipótese deste estudo:

H2: Há relação positiva entre percepção de justiça na avaliação de desempenho e folga de recursos financeiros e humanos.

A não rejeição da hipótese $\mathrm{H} 2$ indicará que os gestores com uma quantidade maior de recursos financeiros e humanos destinados aos seus departamentos, terão maior sentimento de justiça distributiva, processual, interacional e informacional.

\subsubsection{Percepção de justiça na avaliação de desempenho e folga de poder}

A folga de poder é analisada neste estudo por meio da participação orçamentária e autonomia nas decisões. Alguns pesquisadores sugerem que os funcionários envolvidos em processos na organização têm maior percepção de justiça (Folger, Konovsky, 1989).

Conforme Wentzel (1998), a percepção de justiça organizacional aumenta quando o indivíduo participa do processo orçamentário. Magner et al. (2006) especificam que a forma como são determinados os procedimentos orçamentários, tanto de elaboração como de execução, altera as reações dos gestores. Tiller (1983) comenta que a participação orçamentária constitui-se de uma técnica que pode ser utilizada para melhorar as atitudes e comportamento dos gestores, visando a realização dos objetivos propostos pelo orçamento.

Conforme Lindquist (1995), quando os gestores participam do processo orçamentário aumenta a probabilidade do resultado ser justo, além de reforçar a percepção de justiça distributiva, que por consequência aumenta a satisfação e o desempenho. Libby (1999) enfatiza que o indivíduo participando do processo orçamentário, seja por meio da tomada de decisão ou na elaboração de procedimentos, melhora o consentimento das decisões tomadas e aumenta a percepção de justiça processual. Para Maiga e Jacobs (2007), a percepção de justiça distributiva aumenta à medida que surgem mais oportunidades para adquirir dotação orçamentária durante a participação na elaboração do orçamento. Neste sentido, formula-se a terceira hipótese da pesquisa:

H3: Há relação positiva entre percepção de justiça na avaliação de desempenho e participação orçamentária.

Assim, a não rejeição da hipótese $\mathrm{H} 3$ indicará que quanto maior a participação orçamentária, maior será o sentimento de justiça. 
Outra medida relacionada à folga organizacional de poder refere-se ao grau de autonomia dos gestores dos departamentos, o nível de poder de decisão que possuem em sua organização. O nível de autonomia foi utilizado na pesquisa de Indjejikian e Matejka (2006), que investigaram os determinantes da folga organizacional em unidades de negócios de empresas de gestão descentralizada. Os resultados mostraram que a folga é maior quando os controllers das unidades de negócios focalizam mais suas responsabilidades de apoio local do que o controle da matriz. Além disso, que o grau de assimetria de informação entre a matriz e os gestores das unidades de negócios está positivamente associado com folga.

Beck e Beuren (2014, p. 7) explicam que a folga de poder estabelece-se pela autonomia concedida aos diretores, gestores e lideranças na tomada de decisões no planejamento e no processo orçamentário. Acredita-se que esta autonomia ocasiona melhora nos sentimentos de justiça, uma vez que os gestores expressam suas opiniões (voz do processo), estão envolvidos no processo decisório e podem apelar contra decisões desfavoráveis, conforme preceitos da justiça processual. Melhora também a relação interpessoal entre gestores e superiores. Assim, formula-se a quarta hipótese do estudo:

H4: Há relação positiva entre percepção de justiça na avaliação de desempenho e folga de poder sob a forma de autonomia das decisões.

A análise da folga organizacional em uma amplitude maior gera distintos sentimentos de justiça. A participação no processo orçamentário pode gerar maior percepção de justiça (Libby, 1999). A autonomia das decisões suscita sentimentos de justiça processual, interacional e até distributiva, porque várias decisões estão relacionadas à alocação de recursos. Assim, a não rejeição da $\mathrm{H} 4$, indicará que quando os controllers possuem autonomia para decisões, eles percebem maiores sentimentos de justiça.

\section{METODOLOGIA DA PESQUISA}

Estudo descritivo com abordagem quantitativa foi realizado, por meio de pesquisa de levantamento. Um questionário foi enviado aos controllers de 108 empresas das regiões sul e sudeste listadas entre as 150 melhores empresas para se trabalhar, pela revista Você S/A. Houve o retorno de 26 respondentes, o que constituiu-se na amostra por acessibilidade. Neste tipo de amostra, o pesquisador apenas obtém os elementos a que tem acesso, admitindo que eles possam representar de forma adequada a população (Gil, 2008). No entanto, estes resultados não podem ser generalizados, restringem-se aos respondentes da pesquisa.

\subsection{CONSTRUCTO E INSTRUMENTO DA PESQUISA}

A relação da percepção de justiça na avaliação de desempenho e a folga organizacional foram mensuradas utilizando-se das variáveis expostas no constructo da pesquisa, conforme elucidado na Figura 3. 


\begin{tabular}{|c|c|c|}
\hline $\begin{array}{l}\text { Variáveis e } \\
\text { autores }\end{array}$ & Mensuração & Exemplos de assertivas \\
\hline $\begin{array}{l}\text { Justiça } \\
\text { distributiva } \\
\text { (Sotomayor, } \\
\text { 2006). }\end{array}$ & $\begin{array}{l}\text { Foram expostas } 7 \text { assertivas em escala de } \\
1 \text { a } 7 \text {, sendo que } 7 \text { indica alta percepção de } \\
\text { justiça e } 1 \text { baixa percepção de justiça e/ou } \\
\text { sentimento de injustiça. }\end{array}$ & $\begin{array}{l}\text { Dado o seu desempenho, a classificação obtida na sua última } \\
\text { avaliação de desempenho é adequada. } \\
\text { A classificação obtida na sua última avaliação de desempenho } \\
\text { representa um retrato exato e justo do seu desempenho no } \\
\text { trabalho. }\end{array}$ \\
\hline $\begin{array}{l}\text { Justiça } \\
\text { processual } \\
\text { (Sotomayor, } \\
\text { 2006). }\end{array}$ & $\begin{array}{l}\text { Foram expostas } 8 \text { assertivas em escala de } \\
1 \text { a } 7 \text {, sendo que } 7 \text { indica alta percepção de } \\
\text { justiça e } 1 \text { baixa percepção de justiça e/ou } \\
\text { sentimento de injustiça. }\end{array}$ & $\begin{array}{l}\text { As avaliações de desempenho da sua organização são } \\
\text { conduzidas usando procedimentos justos. } \\
\text { Os procedimentos utilizados para obter a sua última } \\
\text { classificação de desempenho foram aplicados de igual modo } \\
\text { a todos os empregados da organização. }\end{array}$ \\
\hline $\begin{array}{l}\text { Justiça } \\
\text { interacional } \\
\text { nterpessoal } \\
\text { (Sotomayor, } \\
\text { 2006). }\end{array}$ & $\begin{array}{l}\text { Foram expostas } 8 \text { assertivas em escala de } \\
1 \text { a } 7 \text {, sendo que } 7 \text { indica alta percepção de } \\
\text { justiça e } 1 \text { baixa percepção de justiça e/ou } \\
\text { sentimento de injustiça. }\end{array}$ & $\begin{array}{l}\text { Durante o processo de avaliação de desempenho o seu } \\
\text { superior hierárquico foi honesto e ético ao lidar consigo. } \\
\text { Durante o processo de avaliação de desempenho o seu } \\
\text { superior hierárquico tratou-o de forma atenciosa. }\end{array}$ \\
\hline $\begin{array}{l}\text { Justiça } \\
\text { interacional } \\
\text { nformacional } \\
\text { (Sotomayor, } \\
\text { 2006). }\end{array}$ & $\begin{array}{l}\text { Foram expostas } 9 \text { assertivas em escala de } \\
1 \text { a } 7 \text {, sendo que } 7 \text { indica alta percepção de } \\
\text { justiça e } 1 \text { baixa percepção de justiça e/ou } \\
\text { sentimento de injustiça. }\end{array}$ & $\begin{array}{l}\text { Durante o processo de avaliação de desempenho o seu } \\
\text { superior hierárquico forneceu-lhe informações adequadas } \\
\text { sobre a sua avaliação. } \\
\text { Durante o processo de avaliação de desempenho você } \\
\text { discutiu com o seu superior hierárquico o modo como o } \\
\text { seu desempenho foi avaliado. }\end{array}$ \\
\hline $\begin{array}{l}\text { Folga quanto } \\
\text { à facilidade no } \\
\text { alcance das metas } \\
\text { orçamentárias } \\
\text { (Indjejikian \& } \\
\text { Matejka, 2006) }\end{array}$ & $\begin{array}{l}\text { Os controllers tiveram que assinalar como } \\
\text { geralmente os objetivos orçamentários são, } \\
\text { em uma escala de } 1 \text { a } 5 \text {, desde fáceis de } \\
\text { atingir a praticamente inatingíveis. Nesta } \\
\text { escala, quanto mais próximo de } 1 \text {, maior é } \\
\text { a folga, e quanto mais próximo de 5, maior } \\
\text { é a inexistência da folga. }\end{array}$ & $\begin{array}{l}\text { No que concerne ao alcance das metas orçamentárias pelo } \\
\text { departamento de controladoria de sua empresa, pode-se } \\
\text { dizer que as metas orçamentárias geralmente são: } \\
\text { 1-Fáceis de atingir } \\
\text { 2- Atingíveis com esforço normal } \\
\text { 3- Atingíveis com elevado esforço } \\
\text { 4-Atingíveis com esforço muito elevado } \\
\text { 5- Praticamente inatingíveis }\end{array}$ \\
\hline $\begin{array}{l}\text { Folga de } \\
\text { recursos } \\
\text { financeiros e } \\
\text { humanos } \\
\text { (Nohria \& Gulati, } \\
\text { 1996; 1997) }\end{array}$ & $\begin{array}{l}\text { Foram expostas situações } \\
\text { hipotéticas em que se solicitou aos } \\
\text { controllers assinalar em uma escala de } \\
1 \text { a } 5 \text { o quanto cada situação afetaria } \\
\text { o desenvolvimento do trabalho da } \\
\text { controladoria. A escala } 1 \text { indica que o } \\
\text { trabalho NÂO seria afetado e a escala } 5, \\
\text { que o trabalho teria uma redução de } 20 \% \\
\text { ou mais. Neste caso, } 1 \text { indica excesso de } \\
\text { recursos no departamento e } 5 \text { indica } \\
\text { inexistência de folga organizacional. }\end{array}$ & $\begin{array}{l}\text { Suponha que devido a algum desenvolvimento súbito, } \\
10 \% \text { do tempo de todas as pessoas que trabalham em seu } \\
\text { departamento precisa ser gasto em trabalho totalmente } \\
\text { desconectado das atribuiçôes e responsabilidades do seu } \\
\text { departamento. Como seu trabalho será afetado durante o } \\
\text { próximo ano? } \\
1 \text { - Trabalho não será afetado } 0 \% \\
2 \text { - Trabalho será afetado até } 5 \% \\
3 \text { - Trabalho será afetado até } 10 \% \\
4 \text { - Trabalho será afetado até } 15 \% \\
5 \text { - Trabalho será afetado até } 20 \% \text { ou mais }\end{array}$ \\
\hline $\begin{array}{l}\text { Folga de poder } \\
\text { sob a forma de } \\
\text { participação } \\
\text { orçamentária } \\
\text { (Leach- López, } \\
\text { Stammerjohan \& } \\
\text { Mcnair, 2007) }\end{array}$ & $\begin{array}{l}\text { Foram expostas } 6 \text { assertivas em escala } \\
\text { de } 1 \text { a } 7 \text {, sendo que } 7 \text { indica alto nível } \\
\text { de participação e } 1 \text { inexistência de } \\
\text { participação. }\end{array}$ & $\begin{array}{l}\text { Estou envolvido na definição de todas as partes do meu } \\
\text { orçamento. } \\
\text { Eu tenho forte influência no valor final do orçamento. }\end{array}$ \\
\hline $\begin{array}{l}\text { Folga de poder } \\
\text { sob a forma de } \\
\text { autonomia nas } \\
\text { decisões } \\
\text { (Indjejikian \& } \\
\text { Matejka, 2006) }\end{array}$ & $\begin{array}{l}\text { Foram expostas } 18 \text { mudanças de aspectos } \\
\text { contábeis em que os controllers tiveram } \\
\text { que atribuir um peso, em uma escala de } \\
1 \text { a } 7 \text {. A escala } 1 \text { significava que "a decisão } \\
\text { sobre a mudança é tomada pelo controller } \\
\text { sem consultar os níveis hierárquicos mais } \\
\text { elevados" e a escala } 7 \text { quando "a decisão } \\
\text { sobre a mudança é tomada pelos níveis } \\
\text { hierárquicos mais elevados, sem consultar } \\
\text { o controller". Assim, quanto mais próxima } \\
\text { de } 7 \text {, menor é a autonomia dos controllers. }\end{array}$ & $\begin{array}{l}\text { Exemplos de mudanças: } \\
\text { Preços de transferência para as transações entre as unidades } \\
\text { de negócios. } \\
\text { Determinação dos relatórios contábeis utilizados na tomada } \\
\text { de decisão } \\
\text { Definição de aumentos salariais do pessoal da controlaria. } \\
\text { Definição de investimentos a serem realizados na } \\
\text { organização } \\
\text { Escolha de artefatos para a tomada de decisão. } \\
\text { Definição do valor do orçamento da área de controladoria. }\end{array}$ \\
\hline
\end{tabular}

Fonte: elaboração própria.

O instrumento de pesquisa consistiu de um questionário direcionado aos controllers das empresas. Com ele procurou-se mensurar as quatro dimensões de percepção de justiça organizacional na avaliação de desempenho, a folga quanto à facilidade no alcance das metas orçamentárias, a folga de recursos financeiros e humanos e a folga de poder (participação orçamentária e autonomia nas decisões). As assertivas das questões foram extraídas das pesquisas de Nohria e Gulati (1996; 1997), 
Indjejikian e Matejka (2006), Sotomayor (2006) e Leach-López, Stammerjohan e McNair (2007), conforme exposto na Figura 3.

\subsection{PROCEDIMENTOS DE ANÁLISE DOS DADOS}

$\mathrm{Na}$ análise dos dados utilizaram-se técnicas de estatística descritiva, correlações de Spearman, análise das componentes principais e correlações canônicas. Na estatística descritiva foram determinados o mínimo e máximo, médias, desvio padrão e coeficiente de variação das variáveis: justiça distributiva, justiça processual, justiça interpessoal, justiça informacional, folga quanto à facilidade no alcance das metas orçamentárias, folga de recursos financeiros, folga de recursos humanos, folga de poder referente à participação orçamentária e folga de poder referente à autonomia.

Inicialmente foram uniformizadas as escalas adotadas. Conforme exposto no Quadro 3 a escala 7 indica alta percepção de justiça e elevada participação orçamentária. Ao passo que para autonomia nas decisões, 1 significa elevado grau de autonomia e 7 sem autonomia. Neste caso, antes de proceder a análise dos dados, reverteram-se as respostas obtidas, em que 7 passou a significar elevado grau de autonomia. 0 mesmo fez-se com as variáveis folga quanto à facilidade no alcance das metas orçamentárias, folga de recursos financeiros e de recursos humanos, em que 5 passou a significar existência de folga organizacional e 1 inexistência.

Em seguida, aplicou-se a técnica de correlação de Spearman, para verificar a força do relacionamento entre as variáveis investigadas. Neste item, analisou-se a relação entre todas as variáveis, analisando-se cada dimensão de justiça organizacional de forma isolada.

Aplicou-se também a técnica estatística da análise das componentes principais (ACPs) nas variáveis do estudo, para depois verificar as correlações canônicas entre grupos de variáveis conforme definido nas hipóteses. Maroco (2007) explica que a técnica da ACPs possibilita sintetizar a informação de diversas variáveis correlacionadas em combinações lineares independentes, de modo que possam representar significativamente a informação das variáveis originais. Dessa maneira, a informação permanece mais confiável do que a aplicação pura e simples da média entre os respondentes.

A técnica de correlações canônicas foi aplicada para analisar a relação entre múltiplas variáveis, por exemplo, a relação entre todas as dimensões de justiça organizacional com a folga de recursos humanos e financeiros. Langevin e Mendoza (2013) comentam que alguns autores têm questionado os benefícios de se concentrar exclusivamente em tipos específicos de justiça, o que sugere uma mudança para examinar julgamentos globais de justiça. De acordo com Colquitt, Greenberg e Scott (2005), a melhor abordagem pode ser examinar as dimensões especificamente e a justiça global em combinação.

\section{DESCRIÇÃO E ANÁLISE DOS DADOS}

\subsection{ESTATÍSTICAS DESCRITIVAS}

Os dados demográficos dos respondentes do instrumento de pesquisa revelam que 17 são do gênero masculino e 9 do gênero feminino. A maioria dos respondentes possui entre 31 a 50 anos, ou seja, 38,5\% se encontram nas faixas entre 31 a 40 anos e $42,3 \%$ entre 41 a 50 anos. A maioria dos respondentes exerce a função de controller corporativo, outros de controller de unidades de 
negócios, supervisor de controladoria, gerente de contabilidade, etc. A maioria exerce a função entre 01 a 10 anos, sendo que 11 respondentes exercem entre 01 a 05 anos e 10 entre 06 a 10 anos. Dos 26 respondentes analisados, todos possuem curso de graduação, 17 possuem especialização, 9 MBA e dois deles inclusive mestrado.

Em relação às empresas, a maioria se constitui em forma de sociedade anônima de capital fechado $(38,5 \%)$ ou sociedade limitada (26,9\%). Quanto ao número de empregados, 7 delas possuem entre a faixa de 1 a 500 empregados, 10 entre 1.001 a 5.000. Entre as empresas respondentes, o menor número de empregados de uma delas é de 105 e a maior possui 8.000. A maioria das empresas já está constituída há mais de 20 anos e atua praticamente em todas as regiões do Brasil, sendo que 13 delas também atuam no mercado externo.

Em relação à sistemática de avaliação de desempenho, em 12 empresas ocorre anualmente e em 10 delas de forma semestral. Em raras empresas ocorre de forma mensal e trimestral. Em 21 empresas o recebimento da remuneração variável está atrelado à realização das metas, sendo que em 20 delas, as metas estão atreladas ao cumprimento do orçamento.

Na Tabela 1 apresentam-se dados relativos à estatística descritiva aplicada em cada variável contida no constructo da pesquisa.

Tabela 1: Aplicação da estatística descritiva nas variáveis investigadas

\begin{tabular}{|c|c|c|c|c|c|}
\hline Variáveis & Mínimo & Máximo & Média & $\begin{array}{c}\text { Desvio } \\
\text { Padrão }\end{array}$ & $\begin{array}{c}\text { Coeficiente } \\
\text { de variação }\end{array}$ \\
\hline Justiça distributiva & 2 & 7 & 6,32 & 0,75 & $11,9 \%$ \\
\hline Justiça processual & 1 & 7 & 6,34 & 0,79 & $12,5 \%$ \\
\hline Justiça interacional interpessoal & 1 & 7 & 6,54 & 0,64 & $9,8 \%$ \\
\hline Justiça interacional informacional & 3 & 7 & 6,30 & 0,73 & $11,6 \%$ \\
\hline $\begin{array}{c}\text { Folga quanto à facilidade no } \\
\text { alcance das metas orçamentárias }\end{array}$ & 2 & 5 & 3,50 & 0,65 & $18,6 \%$ \\
\hline Folga de recursos humanos & 1 & 5 & 3,23 & 1,34 & $41,5 \%$ \\
\hline Folga de recursos financeiros & 1 & 5 & 2,77 & 1,42 & $51,3 \%$ \\
\hline Folga de poder - participação & 3 & 7 & 6,32 & 0,68 & $10,8 \%$ \\
\hline orçamentária & 1 & 7 & 4,02 & 1,37 & $34,1 \%$ \\
\hline
\end{tabular}

Fonte: dados da pesquisa.

Pela Tabela 1, nota-se que os controllers percebem justiça na forma que são avaliados em todas as dimensões e que possuem um elevado grau de participação no orçamento da sua área organizacional. Tal percepção e participação ocorre de forma homogênea entre os respondentes, pois o coeficiente de variação foi inferior a 30\%. A percepção de justiça é semelhante entre as dimensões, com destaque à justiça interpessoal, o demonstra um adequado relacionamento com seus superiores. $O$ fato dos controllers participarem ativamente do processo orçamentário pode corroborar para os sentimentos de justiça, conforme já enfatizado na literatura, que quando os atores estão envolvidos no processo, os sentimentos de justiça aumentam (Leventhal et al., 1980, Folger \& Konovsky, 1989, Wentzel, 1998, Magner et al., 2006). 
Nota-se também que a folga de recursos financeiros é o item que mais se apresenta de forma distinta entre as organizações, obtendo um coeficiente de variação de 51,3\%. Desta forma, percebe-se que em alguns departamentos de controladoria, este tipo de folga está presente, ao passo que em outros, ocorre a inexistência de folga, o que pode resultar no exercício de atividades com maior pressão. As metas orçamentárias, de forma geral, são alcançáveis com esforço normal e/ou com elevado esforço, com uma tendência de pouca folga de recursos financeiros, ao passo que a folga de recursos humanos se manifesta com uma inclinação maior para folga. A folga de recursos humanos pode se manifestar tanto no sentido de número de pessoas para realizar as atividades, como na experiência destes funcionários (Beck, Beuren, 2014).

Além disso, verifica-se que a autonomia das decisões ocorre de forma heterogênea nas empresas, indicando que as funções e atividades dos controllers nas empresas pesquisadas são distintas, o que converge com os resultados da pesquisa de Borinelli (2006), que identificou quatro agrupamentos de empresas cujas práticas de controladoria são homogêneas entre si e heterogêneas entre os grupos. O grau de autonomia dos controllers pode ser uma das justificativas para diferentes manifestações da folga de recursos financeiros e humanos. Conforme Indjejikian e Matejta (2006), a folga organizacional é maior em locais onde os controllers de unidades de negócios se concentram mais em suas responsabilidades de apoio local do que em suas responsabilidades de controle.

\subsection{ANÁLISE DAS CORRELAÇÕES DE SPEARMAN ENTRE AS VARIÁVEIS PESQUISADAS}

Na Tabela 2 evidenciam-se as correlações de Spearman entre as variáveis analisadas na presente pesquisa.

Tabela 2: Correlações de Spearman entre as variáveis da pesquisa

\begin{tabular}{|c|c|c|c|c|c|c|c|c|c|}
\hline Variáveis & JD & $J P$ & JINT & JINF & FO & $\mathrm{FRH}$ & FRF & PA & AUT \\
\hline $\begin{array}{c}\text { Justiça } \\
\text { distributiva (JD) }\end{array}$ & 1,000 & & & & & & & & \\
\hline Justiça processual (JP) & $0,673^{* *}$ & 1,000 & & & & & & & \\
\hline $\begin{array}{l}\text { Justiça interacional } \\
\text { interpessoal (JINT) }\end{array}$ & $0,791^{* *}$ & $0,727^{* *}$ & 1,000 & & & & & & \\
\hline $\begin{array}{l}\text { Justiça interacional } \\
\text { informacional (JINF) }\end{array}$ & $0,784^{* *}$ & $0,638^{* *}$ & $0,801^{* *}$ & 1,000 & & & & & \\
\hline $\begin{array}{c}\text { Folga } \\
\text { quanto à facilidade } \\
\text { no alcance das metas } \\
\text { orçamentárias (FO) }\end{array}$ & 0,022 & 0,374 & 0,160 & 0,006 & 1,000 & & & & \\
\hline $\begin{array}{c}\text { Folga de recursos } \\
\text { humanos (FRH) }\end{array}$ & 0,238 & $0,416^{*}$ & 0,256 & $0,459^{*}$ & 0,226 & 1,000 & & & \\
\hline $\begin{array}{c}\text { Folga de recursos } \\
\text { financeiros (FRF) }\end{array}$ & 0,021 & 0,125 & 0,083 & 0,277 & 0,330 & $0,713^{* *}$ & 1,000 & & \\
\hline $\begin{array}{c}\text { Folga } \\
\text { de } \\
\text { poder - participação } \\
\text { orçamentária (PA) }\end{array}$ & $0,494^{*}$ & $0,438^{*}$ & $0,505^{* *}$ & $0,591^{* *}$ & 0,042 & 0,279 & 0,178 & 1,000 & \\
\hline
\end{tabular}




\begin{tabular}{|l|c|c|c|c|c|c|c|c|c|}
\hline $\begin{array}{l}\text { Folga } \\
\text { de poder-autonomia } \\
\text { nas decisões (AUT) }\end{array}$ & 0,215 & 0,267 & 0,279 & 0,305 & 0,019 & 0,371 & 0,250 & $0,458^{*}$ & 1,000 \\
\hline
\end{tabular}

Correlação significante a 99\%; *Correlação significante a 95\%.

Fonte: dados da pesquisa.

$\mathrm{Na}$ Tabela 2, verifica-se que todas as dimensões de justiça estão correlacionadas entre si, ao nível de significância de $99 \%$, sendo que as associações mais fortes ocorrem entre a justiça informacional com cada uma das outras dimensões, seguida da justiça distributiva e as demais dimensões. Estes resultados coadunam com a pesquisa de Sotomayor (2006), em que as quatro dimensões de justiça organizacional apresentaram-se correlacionadas entre si, porém, o maior destaque foi para a justiça distributiva.

Sotomayor (2006) comenta que alguns pesquisadores entendem que as reações dos indivíduos são melhor explicadas quando consideradas as interações entre as dimensões de justiça. Observa-se que a maior relação foi entre a justiça informacional e a justiça interpessoal, apresentando uma correlação de $80,1 \%$. Tal resultado pode explicar o fato de que alguns pesquisadores, como Masterson et al. (2010), Rupp e Cropanzano (2002), Cohen-Charash e Spector (2001), não classificar a justiça informacional e a interpessoal como dimensões distintas, apenas a consideram como sendo uma terceira dimensão: a interacional. Verifica-se ainda que as dimensões de justiça interacional estão mais relacionadas com a justiça distributiva do que com a justiça processual, o que reforça a separação das dimensões de justiça em pelo menos três, o que diverge dos autores que compreendem que a justiça interacional é uma ramificação da justiça processual.

A compreensão das dimensões de justiça no processo de avaliação de desempenho e seu inter-relacionamento também possui relevância prática. Sotomayor (2006) aduz que tal constatação torna-se relevante para os gestores e organizações, uma vez que podem direcionar os seus esforços para as dimensões de justiça, cujos custos associados forem menores, o que recai normalmente à justiça processual e interacional. Desse modo, o fornecimento de feedback, maior esclarecimento sobre a forma de avaliação, fornecimento de informações adequadas, definição de objetivos claros e precisos auxiliam para obter maior percepção de justiça, inclusive com impacto na justiça distributiva.

Nota-se ainda que a participação orçamentária apresentou correlações significativas com a justiça distributiva, processual e autonomia ao nível de significância de 95\%, e também com a justiça interpessoal e informacional ao nível de significância de 99\%. Todas as correlações foram moderadas, inferiores a $60 \%$, sendo a maior com a justiça informacional, com $59,1 \%$. Tais resultados convergem com o que é difundido na literatura, de que a participação orçamentária aumenta a percepção de justiça por envolver os gestores nos processos, o que já foi confirmado por Tiller (1983), Lindquist (1995), Wentzel (1998), Libby (1999), Magner et al. (2006) e Maiga e Jacobs (2007). 
No entanto, esperava-se uma maior relação com a justiça processual, visto que é a mais enfatizada nos estudos anteriores. Na pesquisa de Wentzel (1998), a participação orçamentária apresentou uma correlação de $45,9 \%$ com a justiça distributiva e $50,4 \%$ com a justiça processual. Por fim, depreende-se que a participação orçamentária aumenta os sentimentos de justiça distributiva, processual e interacional. Por meio dela, os gestores podem obter maiores recursos para suas áreas organizacionais, expor suas necessidades, explicações o que melhora a relação interpessoal, além de considerar o processo consistente, sem viés, ético conforme proposto por Leventhal et al. (1980), e que lhe garante maior autonomia no desenvolvimento de suas atividades.

Quanto aos demais tipos de folga, nota-se que a facilidade no alcance das metas orçamentárias não apresenta nenhuma correlação significativa com as demais variáveis. Isto indica que quando os gestores estão envolvidos no processo orçamentário, o percebem como sendo justo, não tentarão elaborar um orçamento que seja atingível com nenhum esforço, conforme já apontado por Özer e Yilmaz (2011).

Nota-se ainda que a folga de recursos financeiros apenas apresentou correlação significativa e alta com a folga de recursos humanos, o que é coerente, visto que a mesma permite a contratação de um maior número de funcionários, investimentos em cursos e treinamentos, inovação nas tarefas, conforme já destacado por Beck e Beuren (2014).

A folga de recursos humanos apresenta correlações moderadas e significativas com justiça informacional e processual, sendo de $45,9 \%$ e $41,6 \%$ respectivamente. Tais resultados podem decorrer dos procedimentos utilizados pelas empresas para recrutamento e seleção do pessoal, acréscimos salariais, procedimentos usados para avaliação de desempenho, no grau de fornecimento de informações e explicações sobre as decisões que afetam as pessoas. Dessa forma, a folga de recursos humanos (número de pessoas, tempo disponível) permite a realização de tarefas com menor pressão, e ainda permite rever e experimentar processos que possam aumentar o sentimento de justiça, conforme apontado por Lawson (2001).

Portanto, a análise isolada das relações existentes entre as variáveis permite inferir que a justiça organizacional está relacionada com a participação orçamentária e algumas de suas dimensões possuem relação com a folga de recursos humanos. Na próxima seção analisa-se as relações existentes entre o conjunto de dimensões de justiça com os diferentes tipos de folga. Sotomayor (2006) enfatiza que pesquisadores recomendam uma análise integrada das dimensões de justiça e seus efeitos.

\subsection{ANÁLISE DAS CORRELAÇÕES CANÔNICAS ENTRE PERCEPÇÕES DE JUSTIÇA E FOLGA ORGANIZACIONAL}

Após a aplicação da análise das componentes principais, procedeu-se à análise das correlações entre as percepções de justiça na avaliação de desempenho e a folga organizacional dos controllers das empresas pesquisadas. Neste sentido, optou-se pela utilização da técnica estatística de correlação canônica.

Mingoti (2005) explica que a análise das correlações canônicas foi proposta por Hotelling e tem como finalidade principal o estudo das relações lineares existentes entre dois conjuntos de variáveis. Por meio das correlações canônicas é possível verificar a relação entre dois conjuntos de variáveis, o que não é possível na correlação linear. Assim, verificou-se a correlação entre as quatro percepções de justiça e os indicadores de folga organizacional. 
Para o cálculo das correlações canônicas utilizou-se o software Statgraphics, e procedeu-se a análise utilizando 5 correlações com variáveis distintas. Na Tabela 3 apresentam-se as equações canônicas, seus respectivos coeficientes de correlação e o p-value.

Tabela 3: Correlações Canônicas entre Percepções de Justiça e Folga Organizacional

\begin{tabular}{|c|c|c|c|}
\hline Correlações e variáveis & Equação & $\begin{array}{l}\text { Correlação } \\
\text { Canônica }\end{array}$ & P-Value \\
\hline \multirow{3}{*}{$\begin{array}{l}\text { H1: Correlações entre as percepções de } \\
\text { justiça (distributiva, processual, interpessoal e } \\
\text { informacional) com a folga quanto à facilidade no } \\
\text { alcance das metas orçamentárias. }\end{array}$} & $\begin{array}{c}\mathrm{J} 1=-1,66011^{*} \mathrm{JD}+2,02382^{*} \mathrm{JP}+ \\
0,977358^{*} \mathrm{JINT}-1,06762^{*} \mathrm{JINF}\end{array}$ & \multirow{3}{*}{$40,36 \%$} & \multirow{3}{*}{0,4181} \\
\hline & $\mathrm{F} 1=1,0 * \mathrm{FO}$ & & \\
\hline & & & \\
\hline \multirow{2}{*}{$\begin{array}{l}\text { H2: Correlações entre as percepções de } \\
\text { justiça (distributiva, processual, interpessoal e } \\
\text { informacional) com a folga de recursos humanos }\end{array}$} & $\begin{array}{c}J 1=-0,407928^{*} J D+1,11839^{*} \mathrm{JP}- \\
0,609804^{*} \mathrm{JINT}+0,822093^{*} \mathrm{JINF}\end{array}$ & \multirow{2}{*}{$53,66 \%$} & \multirow{2}{*}{0,1130} \\
\hline & $\mathrm{F} 1=1,0 * \mathrm{~F} 53 \mathrm{AP}$ & & \\
\hline \multirow{2}{*}{$\begin{array}{l}\text { H2: Correlações entre as percepções de } \\
\text { justiça (distributiva, processual, interpessoal e } \\
\text { informacional) com a folga de recursos financeiros }\end{array}$} & $\begin{array}{c}J 1=-1,15017^{*} J D-0,208696^{*} J P- \\
0,210015^{*} J I N T+2,07438^{*} J I N F\end{array}$ & \multirow{2}{*}{$39,96 \%$} & \multirow{2}{*}{0,4811} \\
\hline & $\mathrm{F} 1=1,0 * \mathrm{~F} 53 \mathrm{BO}$ & & \\
\hline \multirow{2}{*}{$\begin{array}{l}\text { H3: Correlações entre as percepções de } \\
\text { justiça (distributiva, processual, interpessoal } \\
\text { e informacional) com a participação no } \\
\text { orçamento }\end{array}$} & $\begin{array}{c}\mathrm{J} 1=-0,680995^{*} \mathrm{JD}+0,425963^{*} \mathrm{JP}+ \\
0,730641^{*} \mathrm{JINT}+0,538602^{*} \mathrm{JINF}\end{array}$ & \multirow{2}{*}{$74,64 \%$} & \multirow{2}{*}{0,0027} \\
\hline & $\mathrm{F} 1=1,0 * \mathrm{PO}$ & & \\
\hline \multirow{2}{*}{$\begin{array}{l}\text { H4: Correlações entre as percepções de } \\
\text { justiça (distributiva, processual, interpessoal e } \\
\text { informacional) com a autonomia nas decisões }\end{array}$} & $\begin{array}{c}J 1=-0,785962^{*} \mathrm{JD}+1,21218^{*} \mathrm{JP}+ \\
0,460702^{*} \mathrm{JINT}+0,0603104^{*} \mathrm{JINF}\end{array}$ & \multirow[t]{2}{*}{$64,46 \%$} & \multirow[t]{2}{*}{0,0952} \\
\hline & $\mathrm{F} 1=1,0^{*} \mathrm{AUT}$ & & \\
\hline
\end{tabular}

Ao analisar as dimensões de justiça globalmente com os tipos de folga organizacional, observa-se na Tabela 3 que há correlação forte e significante apenas com participação orçamentária. Um p-value superior a 0,05 indica que não há evidências de que os dados sejam significantes. Assim, não há evidências que as percepções de justiça possuem relação com a folga quanto à facilidade no alcance das metas orçamentárias, folga de recursos humanos, folga de recursos financeiros e autonomia nas decisões. Estes resultados não permitem validar as seguintes hipóteses: H1: Há relação positiva entre percepção de justiça na avaliação de desempenho e folga quanto à facilidade no alcance das metas orçamentárias; H2: Há relação positiva entre percepção de justiça na avaliação de desempenho e folga de recursos financeiros e humanos; e H4: Há relação positiva entre percepção de justiça na avaliação de desempenho e folga de poder sob a forma de autonomia das decisões. 
Entretanto, constatou-se uma correlação forte e significativa, de $74,64 \%$, entre as percepções de justiça e a participação orçamentária. Esses resultados validam a hipótese H3: Há relação positiva entre percepção de justiça na avaliação de desempenho e participação orçamentária. Infere-se que, quando a pessoa participa do processo, no qual realiza sugestões e contribuições, sente-se mais justiçada do que se a participação é menor. Korsgaard e Roberson (1995) mencionam que, quando há participação ou voz nos processos, há efeitos fortes na justiça percebida. Libby (1999) também constatou que a participação dos gestores no processo orçamentário desperta diferentes sentimentos de justiça. Esses resultados ainda coadunam com os de Aryee, Budhwar e Chen (2002), de que a pessoa que participa na tomada de decisão e dos processos na empresa percebe maior justiça organizacional.

Vale lembrar que na Tabela 2 foram apresentadas as relações existentes entre cada dimensão de justiça com diferentes tipos de folga. Ao passo que na Tabela 3, a relação de justiça foi analisada globalmente, ou seja, envolvendo o conjunto das quatro dimensões, com os tipos de folga, o que ocasionou resultados distintos. Isso sugere que as dimensões de justiça possuem efeitos distintos e são conceitualmente independentes uma das outras, principalmente ao considerar a justiça distributiva, justiça processual e justiça interacional, conforme enfatizado por Greeberg (1990) e Sotomayor (2006).

Tais resultados permitem inferir que a relação entre percepção de justiça e folga organizacional ainda não foi explorada suficientemente na literatura, o que enseja estudos adicionais. Talvez até seja possível supor que a folga é um antecedente da justiça organizacional, assim como possivelmente são as políticas salariais, avaliação de desempenho, promoções, processos de seleção. No entanto, pesquisas devem ser realizadas para melhor compreender a relação dessas duas temáticas.

\section{CONSIDERAÇÕES FINAIS}

Esta pesquisa objetivou verificar a relação da percepção de justiça organizacional na avaliação de desempenho com o nível de folga organizacional de controllers sob a forma de recursos financeiros e humanos, de facilidade no alcance das metas orçamentárias e de poder. Observou-se que todas as dimensões de justiça possuem relação com a participação orçamentária. Ao passo que justiça processual e informacional possuem moderada relação com a folga de recursos humanos. Constatou-se ainda que existe relação da folga de recursos financeiros com a folga de recursos humanos e a participação orçamentária, o que sugere a possibilidade de um grau maior de autonomia conferido aos controllers destas empresas.

No que concerne à percepção de justiça organizacional, os controllers pesquisados consideram justas as classificações de desempenho obtidas e que as mesmas refletem a sua contribuição à realização dos objetivos organizacionais. Este resultado está em consonância com a Teoria da Equidade proposta por Adams (1965), em que o indivíduo averigua a existência da proporcionalidade entre as recompensas e o esforço despendido para atingi-las, conforme previsto na justiça distributiva. 
Os controllers pesquisados consideram ainda que as avaliações de desempenho na empresa são conduzidas usando procedimentos justos. Este aspecto é contemplado na justiça processual, que focaliza os meios utilizados para a consecução dos fins alcançados (Rego, 2002; Ribeiro; Batos, 2010). Também que apresentam uma boa relação com seu superior hierárquico, o que converge com o preconizado na justiça interacional, que diz respeito a qualidade da interação dos subordinados com os seus respectivos superiores (Rego, 2002).

Em relação a folga de recursos, observou-se que os recursos financeiros explicam mais a folga organizacional, com grande proximidade aos recursos humanos, o que está alinhado com Mingoti (2005), de que alguns poucos componentes são responsáveis por grande parte da explicação total. $\mathrm{Na}$ análise do nível de participação dos controllers no processo de elaboração do orçamento, destacou-se a contribuição do gestor ao orçamento. Por sua vez, o nível de autonomia dos controllers no processo de decisão é melhor medido pela variável definição do valor do orçamento da área de controladoria. Todavia, todas as categorias de folga analisadas estão presentes em maior ou menor intensidade nas empresas pesquisadas.

$\mathrm{Na}$ análise dos testes de hipóteses, encontram-se evidências para não rejeitar a H3, que existe relação entre percepção de justiça na avaliação de desempenho e participação orçamentária. Por sua vez, as demais hipóteses foram rejeitadas com base nos resultados decorrentes da aplicação das correlações canônicas. Essas evidências suscitam novos estudos, seja em termos de assertivas do instrumento de pesquisa, da ampliação da amostra, ou até mesmo com diferentes técnicas estatísticas.

Assim concluiu-se com base nos resultados da pesquisa que alguns tipos de folga organizacional estão relacionados com os sentimentos de justiça, cujas dimensões têm efeitos distintos. Talvez até seja possível se considerar a folga organizacional como um antecedente da justiça organizacional. Esta reflexão fundamenta-se nas assertivas de que quando a pessoa participa do processo, sente-se mais justiçada (Korsgaard, Roberson, 1995) e que quando a pessoa participa na tomada de decisão e dos processos da empresa, percebe maior justiça organizacional (Aryee, Budhwar \& Chen, 2002).

Entretanto, os resultados não podem ser generalizados, ou seja, restringem-se à população investigada. Destaca-se como limitação da pesquisa, o pequeno número de respondentes, o que impossibilitou ampliar as alternativas de análise dos dados. Outra limitação refere-se à estratégia da pesquisa, que se fundamentou na percepção dos respondentes às questões formuladas. Aspectos subjetivos podem estar presentes no momento da resposta, direcionando-a para uma situação que não seja aquela na qual a empresa se encontra. Outro aspecto a ser destacado é que a percepção de justiça foi analisada a partir da perspectiva dos controllers das empresas investigadas, mas empregados níveis hierárquicos inferiores, que geralmente compõem a grande maioria da força de trabalho, também são afetados pela avaliação e metas de desempenho, bem como de limitações de recursos. 
Apesar das limitações apontadas, este estudo apresenta contribuição teórica, pois vem ampliar pesquisas que buscam possíveis relações entre os dois temas investigados. Para a prática empresarial, o estudo pode consubstanciar práticas de gestão de pessoas e de processos empresariais. Também sinaliza para novas pesquisas, em especial realizar investigação teórico-empírica para verificar se é possível considerar a folga organizacional como um antecedente da justiça organizacional. Pode-se ainda explorar a influência da relação entre folga e percepção de justiça organizacional no desempenho da empresa.

REFERÊNCIAS

Adams, J. Stacy. (1965). Inequity in social exchange. In: Berkowitz, L. (Ed.). Advances in experimental social psychology. New York: Academic Press, 2. pp 267-299.

Ambrose, M. L., Cropanzano, R. (2003). A longitudinal analysis of organizational fairness: An examination of reactions to tenure and promotion decisions. Journal of Applied Psychology, 88 (2), pp. 266-275.

Aryee, S., Budhwar, P. S. \& Chen, Z. X. (2002). Trust as a mediator of the relationship between organizational justice and work outcomes: test of a social exchange model. Journal of Organizational Behavior, 23 (3), pp. 267-285.

Assmar, E. M. L.; Ferreira, M. C.; Souto, S. O. (2005). Justiça organizacional: uma revisão crítica da literatura. Psicologia: Reflexão e Crítica, 18 (3), pp. 443-453.

Beck, F., Beuren, I. M. (2013). Caracterização da folga organizacional no campo empírico: um estudo em empresa do setor têxtil. In: EnANPAD, 37, Rio de Janeiro. Anais... Rio de Janeiro: ANPAD, 2013. CD-ROM.

Beck, F., Beuren, I. M. (2014). Interfaces da folga organizacional com inovação: um estudo em empresa têxtil. In: Congresso ANPCONT, 8, Rio de Janeiro. Anais... São Paulo: ANPCONT, 2014. CD-ROM.

Birnberg, J. G., Luft, J. \& Shields, M. D. (2008). Psychology theory in management accounting research. In: CHAPMAN, C. S.; HOPWOOD, A. G.; SHIELDS, M. D. (Org.). Handbook of Management Accounting Research. Oxford, UK: Elsevier, 1. pp. 113-136.

Blau, G. (1999). Testing the longitudinal impact of work variables and performance appraisal satisfaction on subsequent overall job satisfaction. Human Relations, 5 (8), pp. 1099-1113.

Borinelli, M. L. (2006). Estrutura conceitual básica de controladoria: sistematização a luz da teoria e da práxis. São Paulo, 2006. Tese (Doutorando em Ciências Contábeis) - Universidade de São Paulo, São Paulo, SP, Brasil.

Bourgeois, L. J. (1981). On the measurement of organizational slack. Academy of Management Review, $6(1)$, pp. 29-39. 
Chiuzi, R. M. (2006). As dimensões da organização positiva e seus impactos sobre o bem-estar dos trabalhos. Dissertação (Mestrado em Psicologia da Saúde) - Universidade Metodista de São Paulo, São Bernardo do Campo, SP, Brasil.

Cohen-Charash, Y., Spector, P. E. (2001). The role of justice in organizations: a meta analysis. Organizational Behavior and Human Decision Processes, 86 (2), pp. 278-321.

Colquitt, J. A. (2001). On the dimensionality of organizational justice: a construct validation of a measure. Journal of Applied Psychology, 86 (3), pp. 386-400.

Colquitt, J. A., Conlon, D. E., Wesson, M. J., Porter, C. O. L. H. \& E Ng, K. Y. (2001). Justice at the millennium: A meta-analytic review of 25 years of organizational justice research. Journal of Applied Psychology, 86 (3), 425-445.

Colquitt, J. A., Greenberg, J. \& Scott, B. A. (2005). Organizational justice. Where do we stand? In: Greenberg, J., Colquitt, J. A. (Eds.). Handbook of organizational justice. Mahwa, NJ: Erlbaum Associates, pp. 589-619.

Covaleski, M. A., Evans lii, J. H., Luft, J. L. \& Shields, M. D. (2003). Budgeting research: three theoretical perspectives and criteria for selective integration. Journal Of Management Accounting Research, 15 (1), pp. 3-49.

Cropanzano, R., Prehar, C. A. \& Chen, P.Y. (2002). Using social exchange theory to distinguish procedural from interactional justice. Group \& Organization Management, 27 (3), pp. 324-351.

Cyert, R. M, March, J. G. (1963). A Behavioral Theory of the Firm. Englewood Cliffs, NJ: Prentice-Hall.

Damanpour, F. (1991). Organizational innovation: a meta-analysis of effects of determinants and moderators. Academy of Management Journal, 34 (3), pp. 555-590.

Davila, T., Wouters, M. (2005). Managing budget emphasis through the explicit design of conditional budgetary slack. Accounting, Organizations and Society, 30 (7/8), pp. 587-608.

Deconinck, J. B., Stilwell, C. Dean. (2004). Incorporating organizational justice, role states, pay satisfaction and supervisor satisfaction in a model of turnover intentions. Journal of Business Research, 57 (3), pp. 225-231.

Dimick, D. E., Murray, V.V. (1978). Correlates of substantive policy decisions in organizations: the case of Human Resource Management. Academy of Management Journal, 21 (4), pp. 611-623.

Dunk, A. S. (1990). Budgetary participation, agreement on evaluation criteria and managerial performance: a research note. Accounting Organizations and Society, 15, (3), pp. 171-178. 
Dunk, A.. S., Perera, H. (1997). The incidence of budgetary slack: A field study exploration. Accounting, Auditing \& Accountability Journal, 10 (5), pp. 649-664.

Ferrari, M. J., Cunha, L. C., Lunkes, R. J. \& Borgert, A. (2013). O perfil do controller sob a ótica do mercado de trabalho brasileiro. RIC - Revista de Informação Contábil, 7 (3), pp. 25-50.

Fields, D., Pang, M. \& Chiu, C. (2000). Distributive and procedural justice as predictors of employee outcomes in Hong Kong. Journal of Organizational Behavior, 21 (6), pp. 547-562

Folger, R., Konovsky, M. A. (1989). Effects of procedural and distributive justice on reactions to pay raise decisions. Academy of Management Journal, 32 (1), pp. 115-130.

Folger, R., Skarlicki, D. P. (1999). Unfairness and resistance to change: hardship as mistreatment. Journal of Organizational Change Management, 12 (1), pp. 35-50.

Frezatti, F., Rocha, W., Nascimento, A. R. \& Junqueira, E. R. (2009). Controle gerencial: uma abordagem da contabilidade gerencial no contexto econômico, comportamental e sociológico. São Paulo: Atlas. Gilliland, S. W. (1994). Effects of procedural and distributive justice on reactions to a selection system. Journal of Applied Psychology, 79 (5), pp. 691-701.

Gil, A.C. (2008). Como elaborar projetos de pesquisa. 4. ed. São Paulo: Atlas.

Gilliland, S. W. (1994). Effects of procedural and distributive justice on reactions to a selection system. Journal of Applied Psychology, 79 (5), pp. 691-701.

Gomide JR, S. (1999). Antecedentes e consequentes das percepções de justiça no trabalho. Tese (Doutorado em Psicologia) - Universidade de Brasília, Brasília, Brasil.

Greenberg, J. (1987). Reactions to procedural injustice in payment distributions: do the mean justify the ends? Journal of Applied Psychology, 72 (1), pp. 55-61.

Greenberg, J. (1990). Organizational justice: Yesterday, today and tomorrow. Journal of Management, 16 (2), pp. 399-432.

Greenberg, J. (1993). The intellectual adolescence of organizational justice: You've come a long way, maybe. Social Justice Research, 6 (1), pp. 135-148.

Hopwood, A. G. (1972). An empirical study of the role of accounting data in performance evaluation. Journal of Accounting Research, 10, pp. 56-182.

Indjejikian, R. J., Matejka, M. (2006). Organizational slack in decentralized firms: the role of business unit controllers. The Accounting Review, 81 (4), pp. 849-872. 
Klein, L., Beuren, I. M., Lara, F. L. \& Almeida, L. B. (2014). Percepção de justiça organizacional nos sistemas de controle gerencial aumenta o comprometimento e a confiança dos gestores? In: EnAPAD, 38, Salvador. Anais... Rio de Janeiro: ANPAD, 2014. CD- ROM.

Korsgaard, M. A., Roberson, L. (1995). Procedural justice in performance evaluations: the role of instrumental and non-instrumental voice in performance appraisal discussions. Journal of Management, 21 (4), pp. 657-669.

Langevin, P., Mendoza, C. (2013). How can management control system fairness reduce managers' unethical behaviours? European Management Journal, 31 (3), pp. 209-222.

Lawson, M. B. (2001). In praise of slack: time is of the essence. The Academy of Management Executive, 15 (3), pp. 125-136.

Leach-Lopez, M. A., Stammerjohan, W. W. \& Mcnair, F. M. (2007). Differences in the role of job-relevant information in the budget participation-performance relationship among U.S. and Mexican managers: a question of culture or communication. Journal of Management Accounting Research, 19 (1), pp. 105-136.

Lemons, M. A., Jones, C. A. (2001). Procedural justice in promotion decisions: Using perceptions of fairness to build employee commitment. Journal of Managerial Psychology, 16 (4), pp. 268-280.

Leventhal, G. S. (1980). What should be done with equity theory? New approaches to the study of fairness in social relationships. In: Gergen, K.; Greenberg, M.; Willis, R. (orgs.). Social exchange: new advances in theory and research. New York: Plenum Press.

Libby, T. (1999). The influence of voice and explanation on performance in a participative budgeting setting. Accounting, Organizations and Society, 24 (2), pp. 125-137.

Lindquist, T. M. (1995). Fairness as an antecedent to participative budgeting: examining the effects of distributive justice, procedural justice and referent cognitions on satisfaction and performance. Journal of Management Accounting Research, 7 (1), 1995.

Magner, N. R., Johnson, G. G., Little, H. T., Staley, A. B. \& Welker, R. B. (2006).The case for fair budgetary procedures. Managerial Auditing Journal, 2 (4), pp. 408-419.

Maiga, A. S., Jacobs, F. (2007) 'Budget participation's influence on budget slack the role of fairness perceptions, trust and goal commitment. Journal of Applied Management Accounting Research, 5 (1).

Mallidou, A. A., Cummings, G. G., Ginsburg, L. R., Chuang, Y.-T., Kang, S., Norton, P. G. \& Estabrooks, C. A. (2011). Staff, space, and time as dimensions of organizational slack: A psychometric assessment. Health Care Management Review, 36 (3), pp. 252-264.

Maroco, J. (2007). Análise estatística: com utilização do SPSS. Lisboa: Silabo, 2007. 
Masterson, S. S., Lewis, K., Goldman, B. M. \& Taylor, M. S. (2000). Integrating justice and social exchange: the differing effects of fair procedures and treatment on work relationships. Academy of Management Journal, 43 (4), pp. 738-748.

Merchant, K. A., Manzoni, J. F. (1989). The achievability of budget targets in profit center: a field study. The Accounting Review, 64 (3), pp. 539-558.

Mingoti, S. A. (2005). Análise de dados através de métodos de estatística multivariada: uma abordagem aplicada. Belo Horizonte: UFMG.

Nohria, N., Gulati, R. (1996). Is slack good or bad for innovation? Academy of Management Journal, 39 (5), pp. 1245-1264.

Nohria, N., Gulati, R. (1997). What is the optimum amount of organizational slack? A study of the relationship between slack and innovation in multinational firms. European Management Journal, 15 (6), pp. 603-611.

Omar, A. (2006). Justicia organizacional, individualismo-colectivismo y estrês laboral. Psicologia y Salud, 16 (2), pp. 207-217.

Özer, G., Yilmaz, E. (2011). Effects of procedural justice perception, budgetary control effectiveness and ethical work climate on propensity to create budgetary slack. Business and Economics Research Journal, 2 (4) pp. 1-18.

Pereira, J. B. C. (2008). A relação entre as dimensões de justiça organizacional e as atitudes dos indivíduos diante da diversidade. Tese (Doutorado em Administração de Empresas) - Universidade Presbiteriana Mackenzie, São Paulo, SP, Brasil.

Rego, A. (2002). Comprometimento afectivo dos membros organizacionais: o papel das percepções de justiça. RAC. Revista de Administração Contemporânea, 6 (2), pp. 209-241.

Ribeiro, J. A., Bastos, V. B. (2010). Comprometimento e justiça organizacional: um estudo de suas relações com recompensas assimétricas. Psicologia Ciência e Profissão, 30 (1), pp. 4-21.

Rupp, D. E., Cropanzano, R. (2002). The mediating effects of social exchange relationships in predicting workplace outcomes from multifoci organizational justice. Organizational Behavior and Human Decision Processes, 89 (1), pp. 925-946.

Schiff, M., Lewin, A. Y. (1968). Where traditional budgeting fails. Financial Executive, 36 (5), pp. 51-62. Sotomayor, A. M. S. B. (2006). As percepções de justiça organizacional na avaliação de desempenho: consequências sobre o compromisso organizacional e o compromisso face ao superior hierárquico. Tese (Doutorado em Gestão) - Universidade Técnica de Lisboa, Lisboa, Portugal. 
Sotomayor, A. M. S. B. (2007). Avaliação de desempenho e compromisso organizacional: a perspectiva da justiça organizacional. Revista Universo Contábil, 3 (3), pp. 87-100.

Souto, S., Rego, A. (2003). O modelo tetradimensional da justiça organizacional: uma versão brasileira. Revista de Administração FACES Journal, 2 (2), pp. 9-23.

Tiller, M. G. (1983). The Dissonance model of participative budgeting: an empirical exploration. Journal of Accounting Research, 21 (2).

Tremblay, M., Sire, B. \& Balkin, D. B. (2000). The role of organizational justice in pay and employee benefits satisfaction, and its effects on work attitudes. Group \& Organization Management, 25, (3), pp. 269-290.

Waller, W. (1988). Slack in participative budgeting: the joint effects of a truth-inducing pay scheme and risk preferences. Accounting, Organizations and Society, 13 (1), pp. 87-98.

Van Der Stede, W. A. (2000). The relationship between two consequences of budgetary controls: budget slack creation and managerial short-term orientation. Accounting, Organization and Society, 25 (6), pp. 609-633.

Wentzel, K. N. (1988). Do fairness perceptions of scarce resource allocation decisions influence managers' budgeting behaviors? A test of Organizational Justice Theory. ProQuest Dissertations and Theses, Dissertation (Accounting) - Business and Management Temple University, Philadelphia, PA.

Van Der Stede, W. A. (2000). The relationship between two consequences of budgetary controls: budget slack creation and managerial short-term orientation. Accounting, Organization and Society, 25 (6), pp. 609-633.

Wentzel, K. N. (1988). Do fairness perceptions of scarce resource allocation decisions influence managers'budgeting behaviors? A test of Organizational Justice Theory. ProQuest Dissertations and Theses, Dissertation (Accounting) - Business and Management Temple University, Philadelphia, PA. 